Ying Yu, Yuqiu Yang*, Kazuo Tanabe, Mitsuo Mastuda and Hiroyuki Hamada

\title{
Effect of moisture content of jute fabric and hybridization structure on the impact properties of jute and jute/glass hybrid composites
}

\begin{abstract}
A preliminary investigation on the impact properties and morphologies of unsaturated polyester reinforced with jute woven fabric recycled from used coffee bags with different moisture contents was conducted. The laminated structural effect of hybridization with glass woven fabric was also investigated. Jute/jute-laminated composites, and jute/glass/jute- and jute/jute/glass-laminated hybrid composites were fabricated by the hand lay-up method. Their impact properties were compared by drop-weight and the Izod impact tests. The acoustic emission (AE) technique was applied under a tensile load to detect micro-failure processes in the jute and jute/ glass hybrid composites. The number of AE signals and the $\mathrm{AE}$ energy were monitored using two transducers with resonant frequencies of $140 \mathrm{kHz}$ and $1 \mathrm{MHz}$. The results showed that the moisture content affected the mechanical properties of the composites. The strength and elongation at break of the jute yarn decreased with a decrease in moisture content. The $\mathrm{AE}$ characteristics and observations of the fracture surfaces revealed that the composites fabricated from jute fabric with low moisture content had a relatively higher initial fracture stress and higher resistance to micro-fractures. Moreover, the mechanical properties of the hybrid composites were significantly affected by the laminating structure.
\end{abstract}

Keywords: acoustic emission; glass fiber; hybrid; moisture content; natural fiber.

DOI 10.1515/secm-2013-0147

Received June 23, 2013; accepted September 13, 2014; previously published online January 13, 2015

\footnotetext{
*Corresponding author: Yuqiu Yang, Donghua University, No.2999, Renmin bei Road, Songjiang Qu, Shanghai, 201620, China, e-mail: amy_yuqiu_yang@hotmail.com

Ying Yu and Hiroyuki Hamada: Kyoto Institute of Technology, Matsugasaki, Sakyo-ku, Kyoto, 606-8585, Japan

Kazuo Tanabe and Mitsuo Mastuda: Nicca Chemical Co., Ltd., 23-1, 4-Chome, Bunkyo, Fukui, 910-8670, Japan
}

\section{Introduction}

Owing to the increasing global awareness on environmental and social issues and with the establishment of new environmental regulations, the use of natural fiber-reinforced composites for various applications has been attracting significant attention in recent years $[1,2]$. Because of its low specific mass, low cost and environmental friendliness, the use of natural fiber in place of glass fiber in composites confers numerous benefits in non-structural applications [3]. In particularly, natural fiber composites are promising materials for use in parts of automotives. Given that natural fiber composites have lower weight, their application may result not only in improving vehicle fuel efficiency, but also in assisting in maintaining the sustainability of manufactured materials $[4,5]$. However, the strengths of natural fiber composites are comparably lower than that of their synthetic fiber counterparts. This is often a result of the incompatibility between natural fiber and the resin matrix. In addition, natural fiber is hydrophilic and possesses high moisture absorption potential. Absorption of moisture deforms the surface of the composites by swelling and creating voids. These factors currently limit the large-scale production of natural fiber composites [6-14].

To expand the application of natural fiber composites, several approaches have been taken. Among these, fiber hybridization appears to have significant potential. The production of synthetic/plant fiber hybrid laminates has been explored in recent years with the objective of obtaining materials with sufficient impact properties and other improved mechanical properties while also minimizing costs and ensuring environmental sustainability [15-20]. The most widely used synthetic reinforcement in hybridization is glass fiber because of its high strength, stiffness and corrosion resistance. However, compared with carbon or Kevlar fibers, the use of glass fiber in the military and aerospace industries is disadvantageous because of its susceptibility to impact damage [21, 22]. Nevertheless, by incorporating the glass fibers into natural fiber composites, the penetration resistance and damage tolerance of natural 
fiber composites is greatly improved. Santulli [23] investigated the impact properties of glass/plant fiber hybrid laminates. The successful development of glass/plant fiber hybrid laminates was found to be dependent on the fulfillment of the following conditions: a) introduction of a larger (global) volume of fibers in the composite, b) improved effectiveness of interfaces in dissipating impact damage or improved intermingling of fibers and c) modification of the geometry or study of optimal fiber configurations to maximize impact properties. Morye and Wool [16] explored the mechanical properties of glass/flax hybrid composites based on a novel modified soybean oil matrix material. The mechanical properties of the composites were determined to be dependent on the glass/flax ratio and the arrangement of fibers in the composite. Upon optimal arrangement of fibers in the composite, the glass and flax fibers were found to act synergistically, resulting in an improved flexural and impact performance. Nayak et al. [24] determined the influence of interfacial adhesion on the structural and mechanical behavior of PP-banana/glass hybrid composites. The rate of water absorption in hybrid composites was observed to decrease because of the presence of glass fiber and the coupling agent. Tests revealed that the mechanical properties of the hybrid composites could be improved at certain banana-to-glass ratios and with the coupling agent. Thermal analysis also confirmed an enhancement in the melting point, crystallization temperature and onset thermal degradation temperature.

In a previous work [25], jute fabrics recycled from coffee bags with three different moisture contents were used to fabricate environment-friendly composites by the hand lay-up method. The 3-point bending test, the Izod impact test and the acoustic emission (AE) technique (which was applied under a 3-point bending load) were performed to determine the effect of moisture content of jute fabrics on the mechanical properties of the composites. The results showed that the strength of the jute yarn decreased with a decrease in moisture content. Such findings could explain the lower mechanical properties of composites fabricated from jute fabric with low moisture content. However, the AE characteristics and observation of the fracture surfaces showed that composites fabricated from jute fabric with low moisture content had a relatively higher initial fracture stress and higher resistance to micro-fractures. Moreover, the optical and SEM images of the composites revealed that the interfaces were better in composites with low moisture content.

The performance of natural fiber can be improved by utilizing the hybridization concept. The advantages of one type of fiber can compensate for the disadvantages of the other component fiber. To extend their commercial applicability, it is necessary to clarify the effect of moisture content on hybrid composites and to improve the penetration resistance and damage tolerance of natural fiber composites. In this regard, an expanded preliminary investigation on the impact properties and morphologies of unsaturated polyester reinforced by the recycled jute woven fabric with different moisture contents was conducted. In addition, the effects of hybrid composites with glass woven fabric on laminated structures were investigated by the drop-weight and the Izod impact tests.

\section{Materials and methods}

\subsection{Materials}

Unsaturated polyester (Showa High Polymer Co., Ltd., Tokyo, Japan), jute fabric (recycled from waste coffee bags collected from Coffee Making Company, Japan) and glass fabric (Nitto Glasstex Co., Ltd., Gunma, Japan) were utilized to fabricate composites. The polymer was mixed with the hardener MEKPO (PERMEK N; NOF Corp., Tokyo, Japan) in a ratio of 100:0.7.

Figure 1 shows a photograph and schematic drawing of the jute woven fabric cut from the recycled coffee bags. The type of the jute fabric is plain cloth with an areal density of $0.35 \mathrm{~kg} / \mathrm{m}^{2}$.

\subsection{Fabrication of composites}

The composites were fabricated by the hand lay-up molding method. All jute fabrics were first washed in water and dried naturally at room temperature $(50 \% \mathrm{RH}$, $20^{\circ} \mathrm{C}$ ) to remove contaminants. Prior to the hand lay-up process, some of the jute fabrics were dried further using an oven at $100^{\circ} \mathrm{C}$ for $4 \mathrm{~h}$. Thus, two jute fabrics with two contrasting moisture contents were obtained.
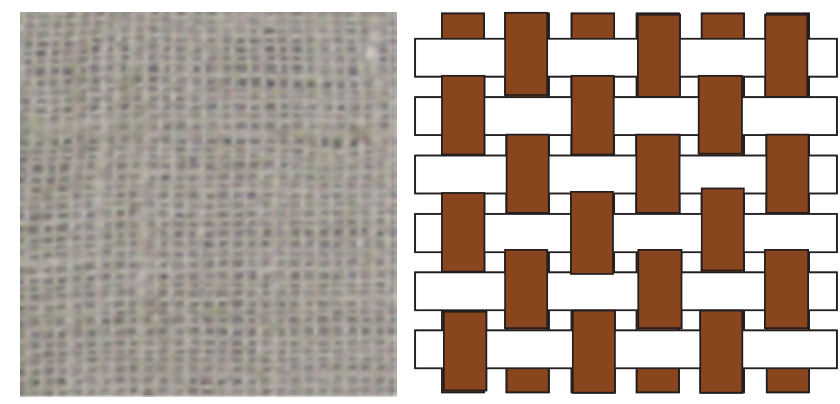

Figure 1 Photograph and schematic drawing of the jute woven fabric. 
Subsequently, the jute fabrics were impregnated with resin and two layers laminated by the hand lay-up method within 2-3 min to maintain a constant water absorption ratio. The thickness of the composites was controlled within $2.6 \mathrm{~mm}-2.9 \mathrm{~mm}$ to obtain a volume fraction of jute fiber of approximately $20 \%$. The jute fabrics were then kept at room temperature for $24 \mathrm{~h}$ to cure the resin before being dried at $100^{\circ} \mathrm{C}$ for $2 \mathrm{~h}$ for post-curing.

Jute/glass (JG) hybrid composites were also made. Compared with the jute fiber, glass fiber does not absorb moisture significantly, so only the moisture content of the jute fabric is discussed in this study. Two kinds of hybrid composite structures were fabricated. Hybrid composites with a laminated structure of jute/glass/jute (JGJ) and jute/jute/glass (JJG) were developed. The volume fractions of jute fiber and glass fiber for both hybrid composite structures were $16.5 \%$ and $1.6 \%$, respectively. Only one glass layer was added while maintaining a standard jute weight content to obtain a better balance between high synthetic and high natural fiber contents.

\subsection{Drop-weight impact test of composites}

The drop-weight impact test was conducted using an Instron dynatup machine (Type $9250 \mathrm{HV}$ ) (Instron, Norwood, MA, USA) under an impact energy of $30 \mathrm{~J}$. The tup size was $12.7 \mathrm{~mm}$. A pneumatic clamping fixture was secured to the tower table, and the fixture was then used to secure a specimen in place prior to an impact test. The fixture size diameter was $76 \mathrm{~mm}$. Each test involved a minimum of three specimen replicates.

\subsection{Izod impact test of composites}

The Izod impact test was performed on an impact tester pendulum 5.5 J (Toyo Seiki Seisaku-sho, Ltd., Tokyo, Japan) in accordance with ASTM D 256-05. The specimens has a dimension of were $10 \times 60 \mathrm{~mm}$ with a V-notch (depth of the notch was $2 \mathrm{~mm}$ with an angle of $45^{\circ}$ ). Each test involved eight specimen replicates.

\subsection{Tensile test and acoustic emission measurement of composites}

Tensile test was conducted using an Instron universal testing machine (Autograph AG-50KNI, Shimadzu Corp., Kyoto, Japan) under a nominal test speed of $1.0 \mathrm{~mm} / \mathrm{min}$ at room temperature and with a gauge length of $100 \mathrm{~mm}$.
During the tensile test, $\mathrm{AE}$ characteristics were monitored simultaneously using 7600 series AE instrumentation (NF Corp., Kanagawa, Japan). Two types of AE transducers with

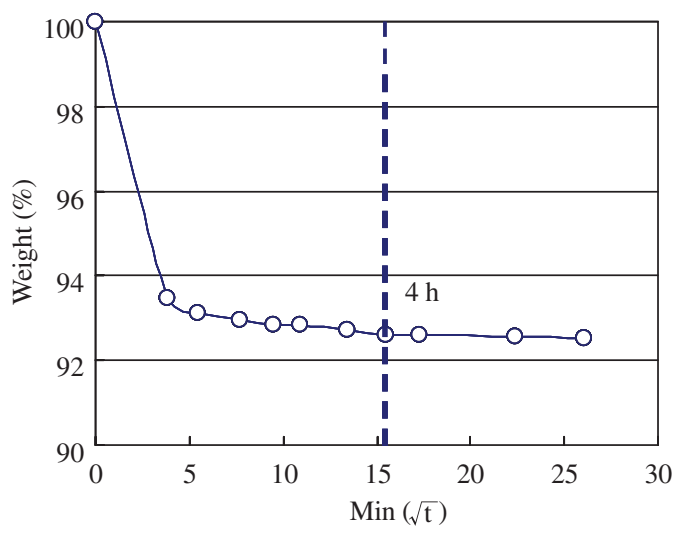

Figure 2 Relationship between the weight of jute fabric and drying time.
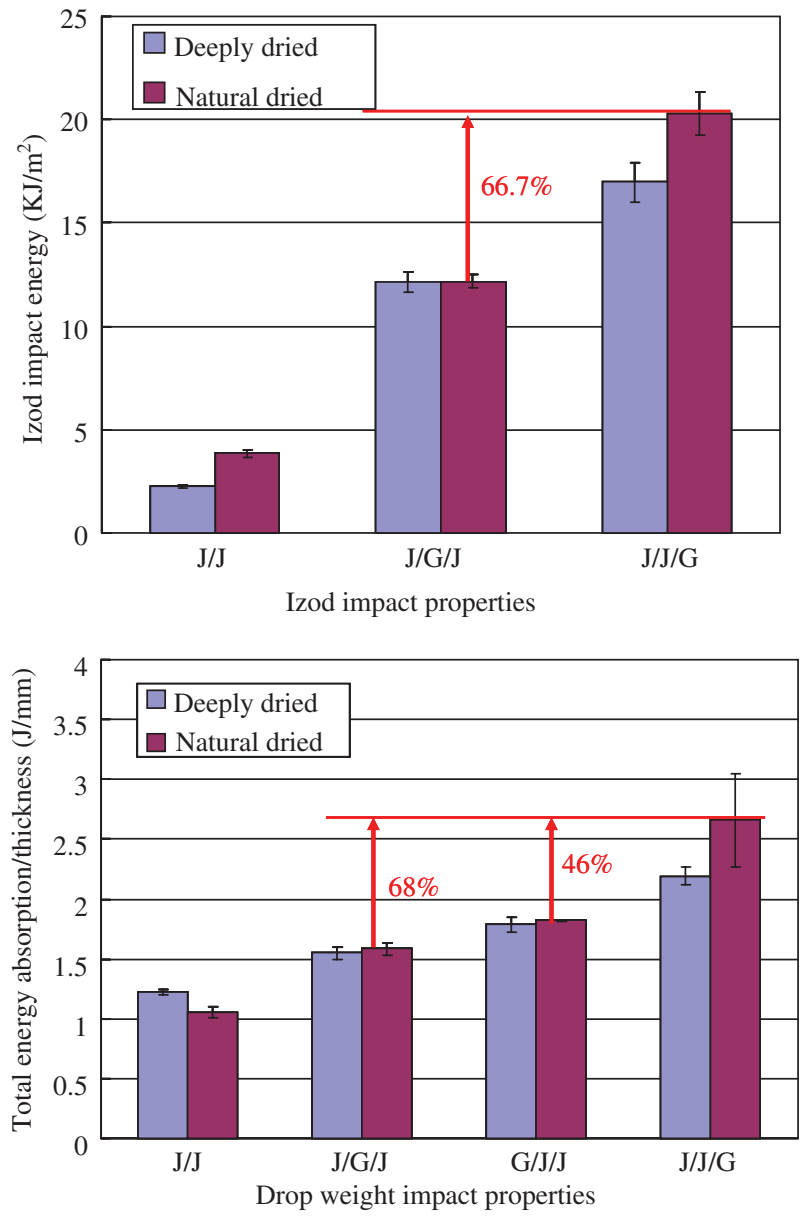

Figure 3 Drop-weight and Izod impact properties of the jute and jute/glass hybrid composites reinforced with jute fabrics with different moisture contents. 
different resonant frequencies of $140 \mathrm{kHz}$ and $1 \mathrm{MHz}$ were attached to the specimens at the center of the width and at two points at a distance of $10 \mathrm{~mm}$ from the central line. The $140 \mathrm{kHz}$ transducer was used to detect matrix cracking or bonding between fiber and matrix, whereas the $1 \mathrm{MHz}$ transducer was employed to detect fiber fracture [26, 27]. The fixed gain was $40 \mathrm{~dB}$, and the threshold was set at $100 \mathrm{mV}$ to reveal the acoustic signal because it is characterized by a higher working frequency compared with the noise frequency. Each test involved five specimen replicates.

\subsection{Optical microscopy and scanning electron microscopy (SEM)}

Post-failure cross-sectional observation was conducted on selected test specimens using an optical microscope and a field-emission scanning electron microscope (Hitachi, S-4200, Hitachi High-Tech Fielding Corp., Tokyo, Japan). Gold was sputtered onto the specimens for electron conductivity before SEM observation.

\section{Results and discussion}

\subsection{Dry processing of the jute fabric and experimental samples}

The relationship between the weight of jute fabric and drying time is shown in Figure 2. A drastic decrease in weight was observed within the first $15 \mathrm{~min}$, but the decrease in weight was very slow thereafter. The final weight of the jute fabric was approximately $92.5 \mathrm{wt} \%$, which means that the moisture content of the jute fabric was about $7.5 \mathrm{wt} \%$. In this study, two drying conditions were applied to the jute fabrics before the hand lay-up molding process to develop two kinds of composites with contrasting moisture contents. As mentioned in section 2.2, some jute fabrics, classified as "deeply dried fabric", were further dried at $100^{\circ} \mathrm{C}$ for $4 \mathrm{~h}$. After $240 \mathrm{~min}$ of drying, the free moisture in the jute fabric had been almost entirely removed. In comparison, the other jute fabrics were not subjected to additional drying and were classified as "naturally dried fabric". The moisture contents were determined to be approximately $0 \mathrm{wt} \%$ for the deeply dried fabric and $7.5 \mathrm{wt} \%$ for the naturally dried fabric. Although the glass fabric was not dried in an oven, the JG hybrid composites were also classified as naturally or deeply dried according to the moisture content of the jute fabric. This classification reflects the relatively low water absorption properties of the glass fabric.
In this study, two different kinds of hybrid composites were fabricated. Both kinds were laminated by two layers of jute fabric and one layer of glass fabric. One kind of hybrid composite structure, classified as the JGJ hybrid composite, involved a glass layer laminated between two jute layers. In the other structures, the glass layer was laminated on one side, and was classified as either the GJJ or the JJG hybrid composite. For the drop-weight impact test, the GJJ composite had the glass layer exposed to the impact tup, whereas the JJG composite had the jute layer as the impact surface.

\subsection{Effect of moisture content on the mechanical properties of composites}

Figure 3 illustrates the drop-weight and the Izod impact properties of the jute and jute/glass hybrid composites
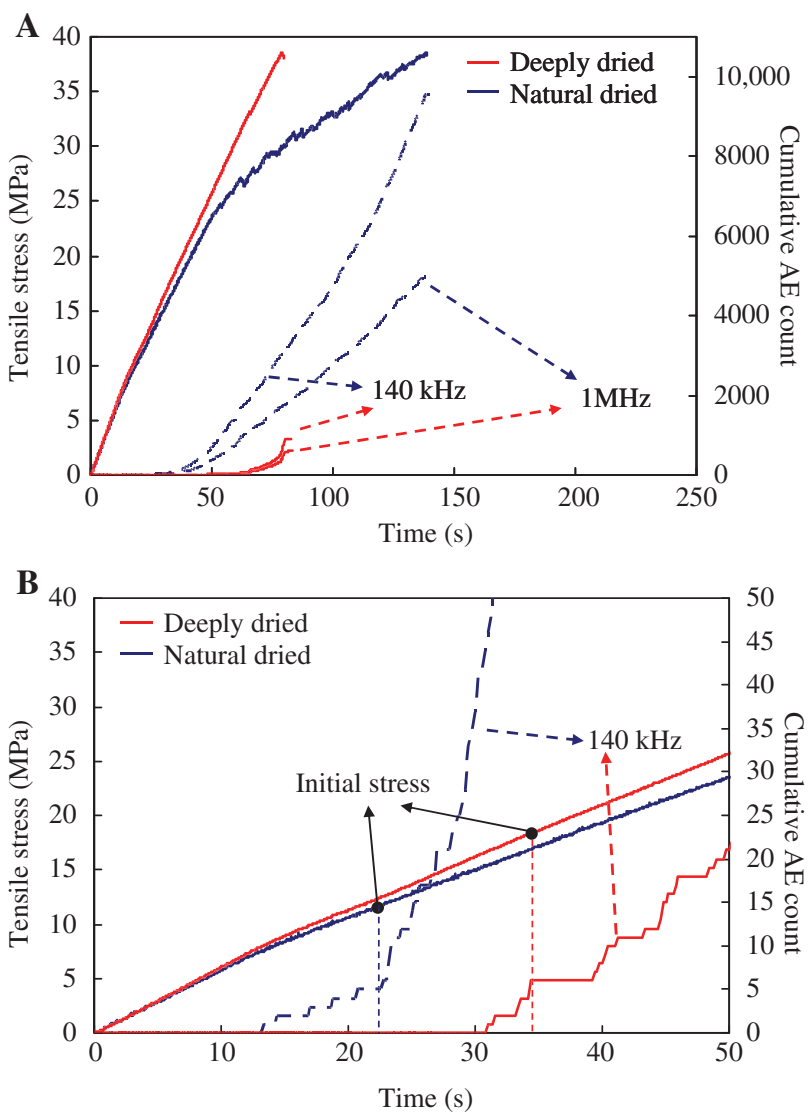

Figure 4 Tensile stress and AE count-time curves of the composites. The deeply dried hybrid composites (jute/glass/jute) had a higher initiation stress and a lower AE count. (A) Tensile stress and AE count-time curves. (B) The beginning stage of tensile stress and $A E$ count-time curve indicated the cumulative $A E$ count has a significant increase when it reached 5 and after that it increased regularly. 


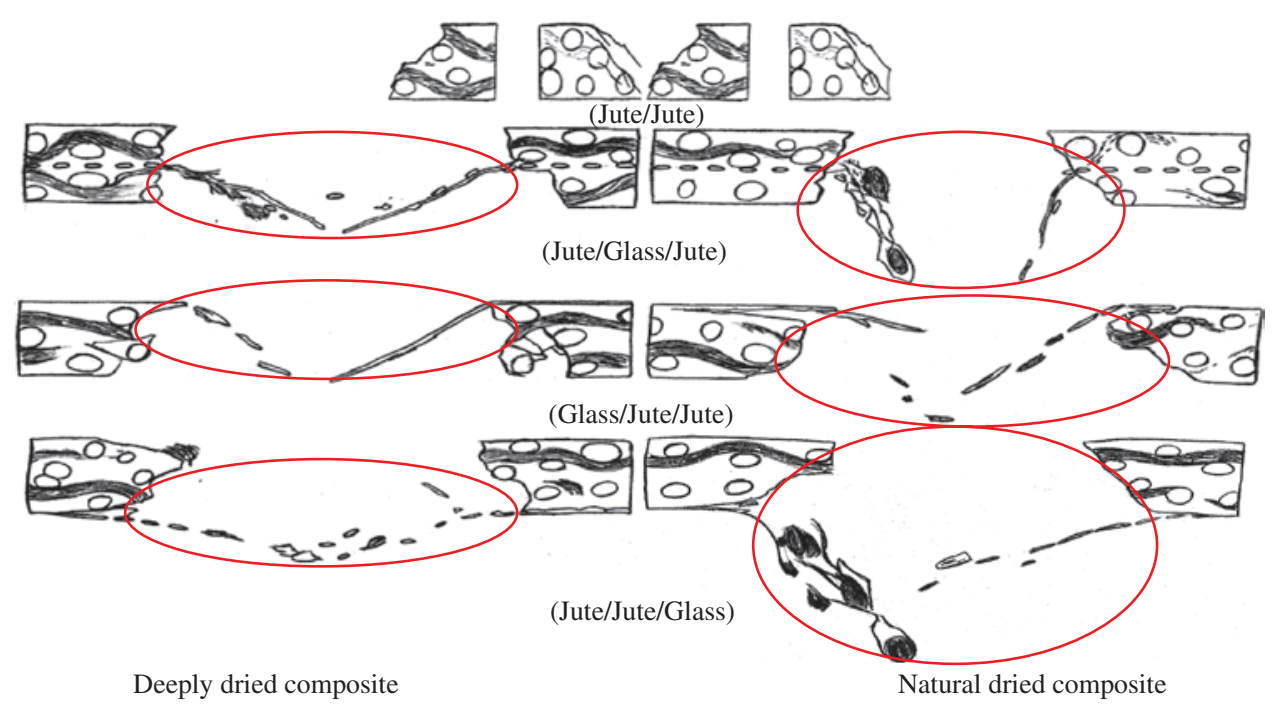

Figure 5 Schematic representation of the reflection-type optical microscope views of the fracture surfaces after the drop-weight impact test. The red circle indicates the fracture area. All of the naturally dried composites, most especially the jute/jute/glass hybrid composites, experienced larger deformation. For the jute/jute composites, the damage area was localized and concentrated. For the hybrid composites, the composites with a jute layer at the impact surface, that is, jute/jute/glass, experienced larger deformation compared with the jute/ glass/jute composite where the glass layer was laminated between two jute layers and the glass/jute/jute composite in which the glass layer was exposed to the impact tup.

reinforced with jute fabrics with different moisture contents. In both tests, almost all of the naturally dried composites showed comparably higher impact properties than the deeply dried composites. Such a finding can be attributed not only to the higher breaking strength per linear density, but also to the higher elongation at the break of naturally dried yarns compared with those of the deeply dried fabrics [25]. Figure 4 shows the tensile stress and the AE count-time curves of both the deeply and naturally dried JGJ hybrid composites. For both specimens, the tensile stress-time relationship increased approximately linearly before $\mathrm{AE}$ initiated. No AE counts were detected, indicating that damage had not yet occurred in the specimen. Afterward, the relationship became non-linear, indicating that micro-cracks were starting to form in the composites. After the AE signals were initiated, the increase in the $\mathrm{AE}$ counts was almost kept constant until the final fracture. In this study, the AE initiation stress was considered as the point when the $140 \mathrm{kHz}$ cumulative $\mathrm{AE}$ count reached five. As shown in Figure $4 \mathrm{~B}$, the cumulative AE count monitored at $140 \mathrm{kHz}$ significantly increased when it reached five, after which it increased regularly. Based on the AE initiation stress, the deeply dried hybrid composite had a higher value than the naturally dried one. The cumulative AE count for the $140 \mathrm{kHz}$ transducer reflects the accumulation of cracks in the matrix. The cumulative AE count for the naturally dried hybrid composite reached approximately 10,000, whereas it was lower, with only about 1000 , for the deeply dried composite. The $1 \mathrm{MHz}$ transducer, which was used to detect the accumulation of fractures in the fibers, also showed higher counts for the naturally dried composite than for the deeply dried composite. Noticeably, multiple matrix cracking and fiber fracturing occurred after AE initiated, and that more micro-cracks formed in the matrix than in the fiber fractures. In particular, the $1 \mathrm{MHz}$ signals were initiated later than the $140 \mathrm{kHz}$ signals, indicating that the fracture of the composites started from the matrix and progressively transferred to the reinforced fibers, eventually resulting in fiber breakage. Consequently, the deeply dried composite is considered to have a relatively higher resistance to micro-fractures. Thus, the composite fabricated from jute fabric with lower moisture content could have a better interfacial adhesion between fiber and matrix.

Based on the observation of the cross-section of the composites shown in Figure 5, the jute fibers were pulled out along the loading direction, whereas the glass layers were delaminated with the matrix in the naturally dried composites. In contrast, the glass layers were still tightly bent to the matrix in the deeply dried composites. In particular, the naturally dried composites, especially the JJG hybrid composites, experienced larger deformation compared with the deeply dried 

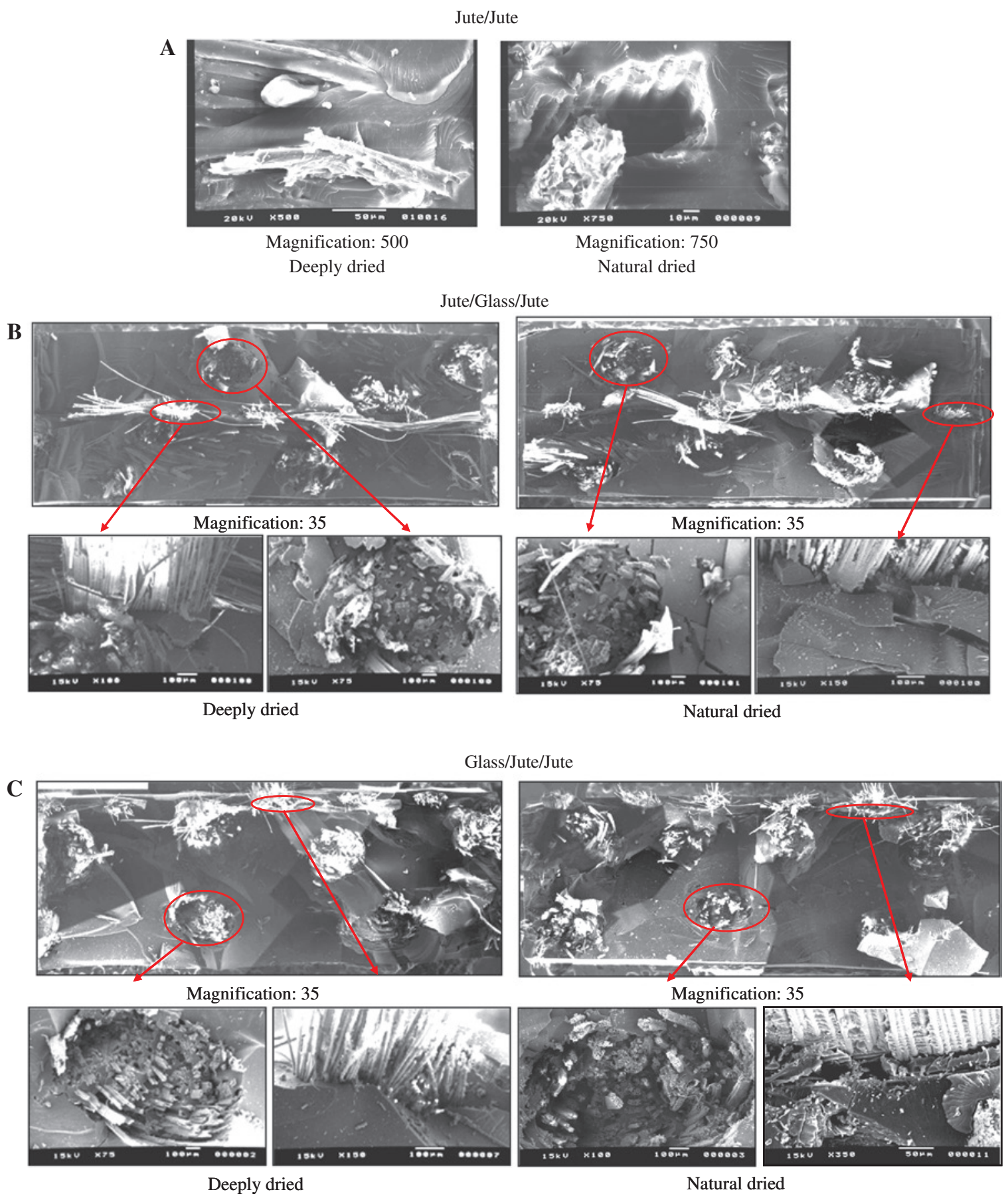

Figure 6 SEM micrographs after the Izod impact test. The bonding between the jute fiber/jute bundle and the matrix was better in the composites with lower moisture content, that is, in deeply dried composites.

ones. The higher elongation at break of the naturally dried jute yarn compared with that of the deeply dried jute fabric accounts for better impact resistance in the former.

The fractures observed on the surface of jute/jute composite after the Izod impact test are shown in Figure 6. In the deeply dried composite, the ruptured fibers were still tightly bent to the matrix, and a thin layer of the matrix was found on the loose fiber surfaces. In the naturally dried composite, fiber bundles were pulled out from the fractured surface, leaving behind large holes. Therefore, the bonding between the jute fiber/jute bundle and the matrix was better in the composite with lower moisture content, i.e., in the deeply dried composite. 

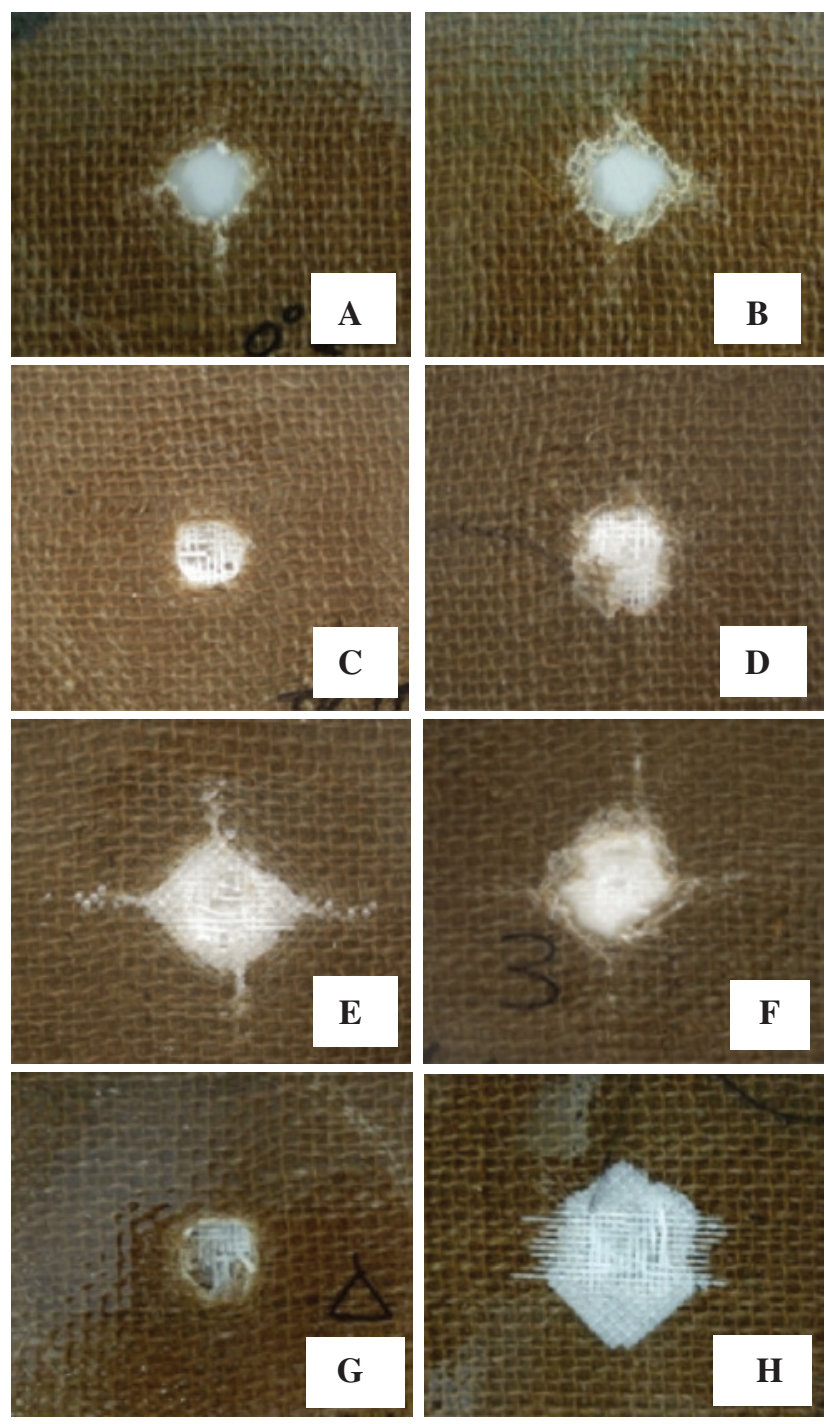

Figure 7 Photographs showing the fracture surfaces after the dropweight impact test. Compared with the jute/jute composites, hybrid composites, especially the jute/jute/glass hybrid composites (hybrid composites with two jute layers directly stuck by the tup), showed larger deformation. (A) Front surface of a jute/jute composite; (B) back surface of a jute/jute composite; (C) front surface of a jute/glass/jute hybrid composite; (D) back surface of a jute/glass/ jute hybrid composite; (E) front surface of a glass/jute/jute hybrid composite; (F) back surface of a glass/jute/jute hybrid composite; (G) front surface of a jute/jute/glass hybrid composite; (H) back surface of a jute/jute/glass hybrid composite.

\subsection{Effect of textile stacking structure with a glass layer on the mechanical properties of the hybrid composites}

As shown in Figure 3, the mechanical properties of the hybrid composites were mainly affected by the stacking structure. For the naturally dried hybrid composites, the

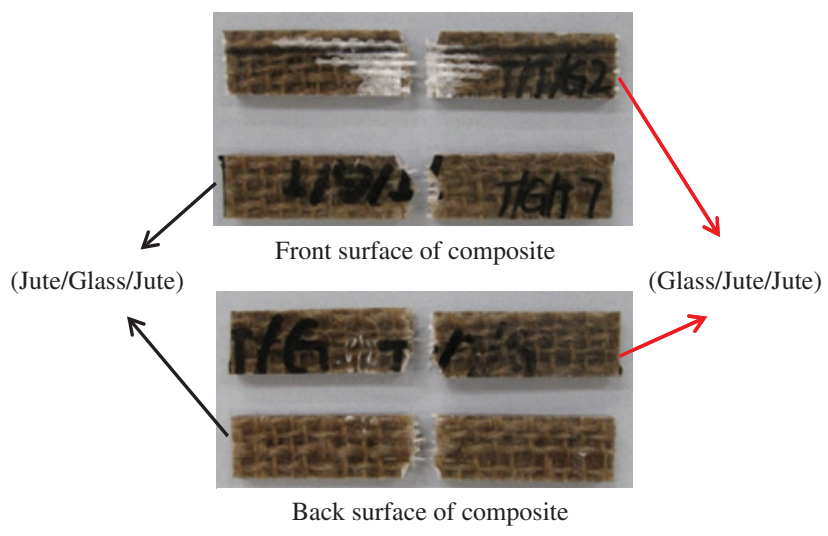

Figure 8 Photographs showing the fracture surfaces of the naturally dried hybrid composites after the Izod impact test. The color white is relative to the delamination of the glass layer.

Izod impact energy of the JJG composites was approximately $66.7 \%$ higher than that of JGJ hybrid composites. Moreover, for the drop-weight impact test, the total energy absorption or thickness value of the jute layer, which was directly struck by the tup, in the JJG composites was $46 \%$ and $68 \%$ higher than that of the GJJ and JGJ composites, respectively, where the glass fabric layer was directly exposed to the impact. These results suggest that the stacking sequence of composites significantly affects the impact behavior of the hybrid composites.

The changes in the fracture surface of the composites after the drop-weight impact test are shown in Figure 7. Compared with the JJ composites, the hybrid composites, especially the JJG hybrid ones, exhibited larger deformation. The relatively higher impact toughness of glass fiber compared with that of jute fiber enhances the perforation resistance of glass hybrid composites, resulting in higher impact energy. Figures 5 and 7 illustrate that the JJ composites were fractured completely and contained a concentrated and localized damage area, which may account for the low impact energy of the JJ composites. The JJG composites with a jute layer at the impact surface clearly experienced larger deformation compared with JGJ and GJJ composites. This observation can be attributed to the higher elongation at break of the jute layer compared with that of the glass layer, resulting in larger deformation and better impact resistance. Moreover, the glass layer in the hybrid composites was effective in extending the break area and may allow for better impact resistance and damage tolerance compared with the JJ composites.

The SEM micrographs of the hybrid composites are shown in Figure 6. The differences between GJJ and JGJ hybrid composites at the fracture surface in the transverse direction were negligible. Figure 8 shows the fracture 
surface of the naturally dried hybrid composites in the longitudinal direction after the Izod impact test. An obvious delamination between the glass layer and matrix in the GJJ hybrid composite can be observed. This delamination might account for the higher Izod impact energy of the GJJ hybrid composites compared with that the JGJ composites.

\section{Conclusion}

In the present study, jute fabric recycled from used coffee bags was utilized to fabricate environment-friendly composites. The effect of moisture content on the mechanical properties of the composites was investigated. The laminated structural effects of the hybridization with glass woven fabric were also investigated.

The moisture content affected the mechanical properties of the composites. The strength and elongation at break of jute yarns decreased with a decrease in moisture content. Moreover, the optical images of the fractures after the drop-weight impact test revealed that the deeply dried composites had better interfacial properties. The naturally dried composites experienced larger deformation, which may be attributed to the higher elongation of the naturally dried jute layer. With regard to the hybrid composites, the glass layer was effective in blunting the propagation of cracks and in increasing impact resistance. The $\mathrm{AE}$ characteristics showed that the composites fabricated from jute fabric with lower moisture content had a relatively higher $\mathrm{AE}$ initiation stress and a higher resistance to micro-fractures.

The addition of a glass layer to the jute layer increased the impact resistance of the composites not only because of the higher strength of glass fiber, but also because the glass layer can increase the damage area of the composite during impact. The position of the glass layer results in variation in the impact behavior of the hybrid composites. When the glass layer was placed at the bottom of the impacted surface, the composites exhibited higher impact energy than those composites with glass fabrics positioned at the top or in the middle layers. Therefore, natural fiber/glass fiber hybridization is an efficient method for expanding the application of natural fiber composites.

\section{References}

[1] Bogoeva-Gaceva G, Avella M, Malinconico M, Buzarovska A, Grozdanov A, Gentile G, Errico ME. Polym. Compos. 2007, 28, 98-107.

[2] Koronis G, Silva A, Fontul M. Compos. Part B, Eng. 2013, 44, 120-127.

[3] Huda MS, Mohanty AK, Drzal LT, Schut E, Misra M. J. Mater. Sci. 2005, 40, 4221-4229.

[4] Westman MP, Laddha SG, Fifield LS, Kafentzis TA, Simmons KL. U.S. Department of Energy, Pacific Northwest National Laboratory, Richland, Washington, 2010.

[5] Larbig H, Scherzer H, Dahlke B, Poltrock R. J. Cell. Plast. 1998, 34, 361-379.

[6] Sawpan MA, Khan MA, Abedin MZ. J. Appl. Polym. Sci. 2003, 87, 993-1000.

[7] Tajvidi M, Najafi SK, Moteei N. J. Appl. Polym. Sci. 2006, 99, 2199-2203.

[8] Khondker OA, Ishiaku US, Nakai A, Hamada H. J. Polym. Environ. 2005, 13, 115-126.

[9] Kim SW, Lee SH, Kang JS, Kang KH. Int. J. Thermophys. 2006, 27, 1873-1881.

[10] Kishore MR. J. Mater. Sci. Lett. 1983, 2, 99-102.

[11] Gassan J, Bledzki A. Polym. Compos. 1997, 18, 179-184.

[12] Karmaker AC. J. Mater. Sci. Lett. 1997, 16, 462-464.

[13] Costa FHMM, D’Almeida JRM. Polym. Plast. Technol. Eng. 1999, 38, 1081-1094.

[14] Akil HM, Cheng LW, Mohd Ishak ZA, Abu Bakar A, Abd Rahman MA. Compos. Sci. Technol. 2009, 69, 1942-1948.

[15] Sreekala MS, George J, Kumaran MG, Thomas S. Compos. Sci. Technol. 2002, 62, 339-353.

[16] Morye SS, Wool RP. Polym. Compos. 2005, 26, 407-416.

[17] De Rosa IM, Santulli C, Sarasini F, Valente M. Compos. Sci. Technol. 2009, 69, 1142-1150.

[18] De Rosa IM, Santulli C, Sarasini F, Valente M. Polym. Compos. 2009, 30, 1879-1887.

[19] Dhakal HN, Zhang ZY, Guthrie R, MacMullen J, Bennett N. Carbohydr. Polym. 2013, 96, 1-8.

[20] Mansor MR, Sapuan SM, Zainudin ES, Nuraini AA, Hambali A. Mater. Des. 2013, 51, 484-492.

[21] Wambua P, Ivens J, Verpoest I. Compos. Sci. Technol. 2003, 63, 1259-1264.

[22] Park R, Jang J. Polym. Compos. 2001, 22, 80-89.

[23] Santulli C. J. Mater. Sci. 2007, 42, 3699-3707.

[24] Nayak SK, Mohanty S, Samal SK. Polym. Compos. 2010, 31, 1247-1257.

[25] Ying Y, Yuqiu Y, Kazuo T, Mitsuo M, Hiroyuki H. J. Biobased. Mater. Bio. 2011, 5, 117-123.

[26] Morii T, Jumonji N, Fujita T, Horie T. Proceedings of the 10th Japan International SAMPE Symposium and Exhibition, CD-ROM, 2007.

[27] Morii T, Fujita T. ANTEC 2009, 580-584. 